UDC 544.72

Author: AYZENSHTADT Arkady Mikhailovich, Doctor of Chemistry, Professor, Honored Worker of Higher Education of the Russian Federation, Head of Composite Materials and Engineering Ecology Department, Northern (Arctic) Federal University named after M.V. Lomonosov, Institute of Construction and Architecture, Department of Composite Materials and Engineering Ecology; Northern Dvina Emb. 17, Arkhangelsk, Russia, 163002; a.isenshtadt@narfu.ru;

Author: FROLOVA Maria Arkadevna, PhD in Chemistry, Associated Professor of Composite Materials and Engineering Ecology Department, Northern (Arctic) Federal University named after M.V. Lomonosov; Severnaya Dvina Emb., 17, Arkhangelsk, Russia, 163002, aizenmaria@gmail.com; Author: SHINKARUK Anna Alexandrovna, PhD in Chemistry, Associated Professor of Composite Materials and Engineering Ecology Department, Northern (Arctic) Federal University named after M.V. Lomonosov; Severnaya Dvina Emb., 17, Arkhangelsk, Russia, 163002, a.shinkaruk@narfu.ru

\title{
COMPREHENSIVE METHODOLOGICAL APPROACH TO DETERMINE THE TOXICOLOGICAL CHARACTERISTICS OF THE HIGHLY DISPERSED ROCK SAMPLES
}

\section{ExTENDED Abstract:}

A schematic diagram of the integrated approach for assessing the toxicological properties of rocks, taking into account their physicochemical properties, was proposed. This methodology was tested on the basalt samples taken from the Myandukha deposit (Arkhangelsk region). The paper presents data of the chemical composition on the basis of which the value of the specific mass energy of atomization of the raw material of the rock was calculated. The energy parameters of the micro- and nanosystems of the sample were calculated: free surface energy and surface activity. To perform toxicological evaluation of the analyzed material a new generation sequencing (NGS) method, the metagenomic analysis, and the MTT method for determining the viability of cell cultures were used. These methods allowed determining species diversity of microorganisms in basalt samples, as well as the cytotoxicity of highly dispersed basalt particles. It was found out that basalt, possessing a high surface activity, is capable of sorbing significant number of microorganisms of different species groups on the surface of the particles, that is a potential danger of microbiological contamination - this fact must be taken into account when processing raw materials in technological 
processes. At the same time, the non-toxic nature of the basalt nanoparticles was noted. The proposed schematic diagram of the integrated approach can be recommended for assessing the toxicological properties of rocks.

Key words: rocks, basalt, nanoparticles, free surface energy, surface activity, toxicity, cytotoxicity.

DOI: dx.doi.org/10.15828/2075-8545-2017-9-6-91-106

\begin{abstract}
MACHine-REAdAble information on CC-LiCENSES (HTML-CODE) IN METAdATA OF THE PAPER
$<$ a rel="license" href="http://creativecommons.org/licenses/by/4.0/" $><$ img alt="Creative Commons License" style="borderwidth:0" src="https://i.creativecommons.org/l/by/4.0/88x31.png" $/></ \mathrm{a}><$ br $/><$ span xmlns:dct="http://purl.org/dc/ terms/" href="http://purl.org/dc/dcmitype/Text" property="dct:title" rel="dct:type" $>$ Comprehensive methodological approach to determine the toxicological characteristics of the highly dispersed rock samples $</$ span $>$ by $<$ a xmlns:cc="http:// creativecommons.org/ns\#" href="Nanotehnologii v stroitel'stve = Nanotechnologies in Construction. 2017, Vol. 9, no. 6, pp. 91-106. DOI: dx.doi.org/10.15828/2075-8545-2017-9-6-91-106" property="cc:attributionName" rel="cc:attrib utionURL">Ayzenshtadt A.M., Frolova M.A., Shinkaruk A.A. $</ a>$ is licensed under a $<$ a rel="license" href="http:// creativecommons.org/licenses/by $/ 4.0 / ">$ Creative Commons Attribution 4.0 International License $</ \mathrm{a}>$. $<$ br $/>$ Based on a work at $<$ a xmlns:dct="http://purl.org/dc/terms/" href=" http://nanobuild.ru/en_EN/nanobuild-6-2017/" rel="dct:source" $>$

http://nanobuild.ru/en_EN/nanobuild-6-2017/</a $>$. $<$ br $/>$ Permissions beyond the scope of this license may be available at $<$ a xmlns:cc="http://creativecommons.org/ns\#"href="aizenmaria@gmail.com"rel="cc:morePermissions">aizenmaria@gmail. $\operatorname{com}</ \mathrm{a}>$.
\end{abstract}

\title{
References:
}

1. Godymchuk A.Yu. Ekologiya nanomaterialov [Ecology of nanomaterials]. Moscow, Binom, 2012. (In Russian).

2. Tretyakov Yu.D., Gudilin E.A. Osnovnye napravleniya fundamental'nyh i orientirovannyh fundamental'nyh issledovanij v oblasti nanomaterialov [The main directions of fundamental and oriented fundamental research in the field of nanomaterials]. Al'ternativnaya ehnergetika i ehkologiya [Alternative energy and ecology]. 2009, № 6, p. 39-67. (In Russian).

3. Lesovik V.S., Strokova V.V. O razvitii nauchnogo napravleniya «Nanosistemy v stroitel'nom materialovedenii» [About the development of the scientific direction «Nanosystems in Building Materials Science»]. Stroitel'nye materialy [Construction Materials]. 2006, № 9, p. 18-20. (In Russian).

4. Karpov A.I. Razvitie nanotekhnologij v stroitel'stve - aktual'nejshaya zadacha uchenyh i inzhenerov [Development of nanotechnologies in construction - a task which is of great importance for scientists and engineers. Part 5.] Nanotehnologii 
$\mathrm{v}$ stroitel'stve $=$ Nanotechnologies in Construction. 2013, Vol. 5, no. 2, pp. 4354. URL: http://nanobuild.ru/magazine/nb/Nanobuild_2_2013.pdf (Accessed: 01.11.2017). (In Russian).

5. Artamonova O.V., Sergutkina O.R., Korotkikh D.N., Chernishov E.M. Zol'-gel' sintez nanorazmernyh chastic $\mathrm{SiO}_{2}$ dlja modificirovanija struktury cementnogo kamnja [Sol-gel synthesis of $\mathrm{SiO}_{2}$ nanosized particles for cement stone structure modifying.] Nanotehnologii v stroitel'stve = Nanotechnologies in Construction. 2010, Vol. 2, no. 1, pp. 9-17. Available at: http://www.nanobuild.ru/magazine/ nb/Nanobuild_1_2010.pdf (Accessed 01.02.2016). (In Russian).

6. Fathutdinova L.M., Haliullin T.O., Zalyalov R.R. Toksichnost' isskustvennyh nanochastic [Toxicity of artificial nanoparticles]. Kazanskij medicinskij zhurnal [Kazan Medical Journal]. 2009, p. 578-584. (In Russian).

7. Danilov V.E., Ayzenshtadt A.M., Bessert O.B. Optimization of the composite binder on the basis of basalt and polymineral sand. In Proc. of Conference «International Conference on Electrical, Electronics, and Optimization Techniques» (ICEEOT-2016), Tamil Nadu, India. 2016. P. 192-195.

8. Drozdyuk T., Aizenshtadt A., Tutygin A. and Frolova M. Basalt fiber insulating material with a mineral binding agent for industrial use. IOP Conference Series: Materials Science and Engineering. 2016, Vol. 124, N 1, p. 1-4.

9. Stenin A.A., Ajzenshtadt A.M., Shinkaruk A.A., Demidov M.L., Frolova M.A. Mineral'nyj modifikator poverhnosti stroitel'nyh materialov iz drevesiny [Mineral surface modifier of wooden building materials]. Stroitel'nye materialy [Construction Materials]. 2014, № 10, p. 51-54. (In Russian).

10. Fomichev S.V., Babievskaya I.Z., Dergacheva N.P., Noskova O.A., Krenev V.A. Ocenka i modificirovanie iskhodnogo sostava gabbro-bazal 'tovyh porod dlya polucheniya mineral'nyh volokon i izdelij kamennogo lit'ya [Evaluation and modification of the initial composition of gabbro-basalt rocks for the production of mineral fibers and stone casting products]. Neorganicheskie materialy [Inorganic materials]. 2010, Vol. 46, № 10, p. 1240-1245. (In Russian).

11. Anciferova I.V., Makarova E.N. Metody proizvodstva nanomaterialov i vozmozhnye ehkologicheskie riski [Methods of production of nanomaterials and possible environmental risks]. Vestnik PNIPU. Mashinostroenie, materialovedenie [Bulletin PNRPU. Mechanical engineering, materials science]. 2013, Vol. 15, № 4, p. 59-67. (In Russian).

12. Veshnyakova L.A., Ajzenshtadt A.M., Frolova M.A. Ocenka poverhnostnoj aktivnosti vysokodispersnogo syr'ya dlya kompozicionnyh stroitel'nyh materialov [Evaluation of the surface activity of highly disperse raw materials for composite building materials]. Fizika i ximiya obrabotki materialov [Physics and Chemistry of Material Processing]. 2015, № 2, p. 68-72. (In Russian). 
13. Abramovskaya I.R., Ayzenshtadt A.M., Frolova M.A., Veshnyakova L.A., Tutygin A.S. Energetika vysokodispersnyh kompozitov gornyh porod [The energy of highly dispersed rock composites]. Nanotehnologii v stroitel'stve = Nanotechnologies in Construction. 2013, Vol. 5, no.3, p. 56-65. (In Russian).

14. Abramovskaya I.R., Ajzenshtadt A.M., Lesovik V.S., Veshnyakova L.A., Frolova M. A., Kazlitin S.A. Raschet ehnergoemkosti gornyh porod - kak syr'ya dlya proizvodstva stroitel'nyh materialov [Calculation of the energy intensity of rocks as raw material for the production of building materials]. Promyshlennoe i grazhdanskoe stroitel'stvo [Industrial and civil construction]. 2012, № 10, p. 23-25. (In Russian).

15. Smirnov V.A., Korolev E.V., Albakasov A.I. Razmernye ehffekty i topologicheskie osobennosti nanomodificirovannyh kompozitov [Size effects and topological features of nanomodified composites]. Nanotehnologii v stroitel'stve = Nanotechnologies in Construction. 2011, Vol. 3, no. 4, pp. 17-27. URL:http://nanobuild.ru/ magazine/nb/Nanobuild_4_2011.pdf (Accessed: 01.11.2017). (In Russian).

16. Gayda J., Ayzenshtadt A., Tutygin A., Frolova M. Organic-Mineral Aggregate for Sandy Subsoil Strengthening.Procedia Engineering, 2016, Vol. 143, p. 90-97.

17. Frolova M.A., Tutygin A.S., Aizenshtadt A.M., Lesovik V.S., Mahova T.A., Pospelova T.A. Kriterij ocenki ehnergeticheskih svojstv poverhnosti [A criterion for estimating the energy properties of a surface]. Nanosistemy: fizika, himiya, matematika [Nanosystems: Physics, Chemistry, Mathematics]. 2011, Vol. 2, № 4, p. 120-125. (In Russian).

18. Veshnyakova L.A., Drozdyuk T.A., Ajzenshtadt A.M., Frolova M.A., Tutygin A.S. Poverhnostnaya aktivnost' kremnesoderzhashchih gornyh porod [Surface activity of siliceous rocks]. Materialovedenie [Material Science]. 2016, №5, p. 45-48. (In Russian).

19. Ansorge W.J. Next-generation DNA sequencing techniques.N Biotechnol. 2009. Apr; 25(4). P. 195-203.

20. Wilson Anne P. Chapter 7: Cytotoxicity and viability. Animal Cell Culture: A Practical Approach Oxford: Oxford University Press. 2000. Vol. 1. 334 p. ISBN 978-019-963796-6.

\section{Dear COlleagues!}

THE REFERENCE TO THIS PAPER HAS THE FOLLOWING CITATION FORMAT:

Ayzenshtadt A.M., Frolova M.A., Shinkaruk A.A. Comprehensive methodological approach to determine the toxicological characteristics of the highly dispersed rock samples. Nanotehnologii v stroitel'stve $=$ Nanotechnologies in Construction . 2017, Vol. 9, no. 6, pp. 91-106. DOI: dx.doi.org/10.15828/2075-8545-2017-9-691-106. (In Russian). 
Автор: АЙЗЕНШТАДТ Аркадий Михайлович, проф., д.х.н., зав. каф. композиционных материалов и строительной экологии, Северный (Арктический) федеральный университет имени М.В. Ломоносова; наб. Северной Двины, 17, г. Архангельск, Россия, 163002 , a.isenshtadt@narfu.ru;

Автор: ФРОЛОВА Мария Аркадьевна, к.х.н., доц. каф. композиционных материалов и строительной экологии, Северный (Арктический) федеральный университет имени М.В. Ломоносова; наб. Северной Двины, 17, г. Архангельск, Россия, 163002 , aizenmaria@gmail.com;

Автор: ШИНКАРУК Анна Александровна, к.х.н., доц. каф. композиционных материалов и строительной экологии, Северный (Арктический) федеральный университет имени М.В. Ломоносова; наб. Северной Двины, 17, г. Архангельск, Россия, 163002, a.shinkaruk@narfu.ru

\section{КОМПЛЕКСНЫЙ МЕТОДОЛОГИЧЕСКИЙ ПОДХОД ДЛЯ ОПРЕДЕЛЕНИЯ ТОКСИКОЛОГИЧЕСКИХ ХАРАКТЕРИСТИК ТОНКОДИСПЕРСНЫХ ОБРАЗЦОВ ГОРНЫХ ПОРОД}

АННОТАЦИЯ К СТАТЬЕ (АВТОРСКОЕ РЕЗЮMЕ, РЕФЕРАТ):

Предложена принципиальная схема комплексного подхода для оценки токсикологических свойств горных пород, учитывающая их физико-химические свойства. Методология апробирована на опытных образцах базальта, отобранных с месторождения «Мяндуха» (Архангельская область). Представлены данные по химическому составу, на основании которого рассчитана величина удельной массовой энергии атомизации сырьевого материала горной породы. Проведен расчет энергетических параметров микро- и наносистем исследуемого образца: свободной поверхностной энергии и поверхностной активности. Для токсикологической оценки анализируемого материала использованы метод секвенирования нового поколения (СНП), метагеномный анализ и МТТ-метод определения жизнеспособности клеточных культур. Данные методы позволили определить видовое разнообразие микроорганизмов в исходных образцах базальта, а также цитотоксичность тонкодисперсных частиц базальта. Установлено, что базальт, обладая высокой поверхностной активностью, способен сорбировать на поверхности частиц значительное количество микроорганизмов различных видовых групп, что представляет со- 
бой потенциальную опасность микробиологического заражения - данный факт необходимо учитывать при переработке сырья в технологических процессах. Вместе с тем, отмечена нетоксичная природа самих наночастиц базальта. Предложенная принципиальная схема комплексного подхода может быть рекомендована для оценки токсикологических свойств горных пород.

Ключевые слова: горные породы, базальт, наночастицы, свободная поверхностная энергия, поверхностная активность, токсичность, цитотоксичность.

DOI: dx.doi.org/10.15828/2075-8545-2017-9-6-91-106

МАШИНОЧИТАЕМАЯ ИНФОРМАЦИЯ О CC-ЛИЦЕНЗИИ В МЕТАДАННЫХ СТАТЬИ (HTML-КОД):

$<$ a rel="license" href="http://creativecommons.org/licenses/by/4.0/"><img alt="Лицензия Creative Commons" style="borderwidth:0" src="https://i.creativecommons.org/l/by/4.0/88x31.png" $/></ \mathrm{a}><$ br $/>$ Произведение «<span xmlns:dct="http:// purl.org/dc/terms/" href="http://purl.org/dc/dcmitype/Text" property="dct:title" rel="dct:type"> Комплексный методологический подход для определения токсикологических характеристик тонкодисперсных образцов горных пород </span>» созданное автором по имени <a xmlns:cc="http://creativecommons.org/ns\#" href="Нанотехнологии в строительстве. -2017. - Том 9, № 6. - C. 91-106. - DOI: dx.doi.org/10.15828/2075-8545-2017-9-6-91-106." property="cc:attributionName" rel= "cc:attributionURL"> Айзенштадт A.M., Фролова M.А., Шинкарук А.А. $</$ a $>$, публикуется на условиях $<$ a rel="license" href="http://creativecommons.org/licenses/by/4.0/">лицензии Creative Commons «Attribution» («Атрибуция») 4.0 Всемирная $</ \mathrm{a}>$. $<$ br $/>$ Основано на произведении с $<$ a xmlns:dct="http://purl.org/dc/terms/" href="http://nanobuild.ru/ ru_RU/nanobuild-6-2017/" rel="dct:source">http://nanobuild.ru/ru_RU/nanobuild-6-2017/</a >.<br />Разрешения, выходящие за рамки данной лицензии, могут быть доступны на странице $<$ a xmlns:cc="http://creativecommons.org/ns\#" href="aizenmaria@gmail.com" rel="cc:morePermissions">aizenmaria@gmail.com</a> .

\section{Введение}

Способность инертных материалов, практически безвредных для организма человека, становиться опасными при высокой степени дисперсности - известный факт, не связанный с появлением нанотехнологий. Это объясняется, прежде всего, неспособностью легких перерабатывать или удалять наночастицы, вызывая при этом рефлекторное сужение бронхиол и альвеол, что приводит к снижению количества кислорода в крови. Поэтому, при создании и использовании наноматериалов, вопросы прогнозирования влияния наночастиц на здоровье людей и экологию окружающей среды являются актуальными. В настоящее время выделяют три основные причины вредного воздействия наноча- 
стиц на здоровье человека [1-2]. Первая - токсичным может быть основное вещество наночастиц. Вторая - некоторые наночастицы, не проявляя токсичных свойств, связанных с их химическим составом, могут выступать в роли катализаторов образования токсичных веществ. Третья - специфическое действие на организм, связанное с размерными эффектами.

Индустрия производства строительных материалов основана на использовании в качестве основных сырьевых ресурсов горных пород различного генезиса [3-5]. Однако при этом, на сегодняшний день, нет сведений о влиянии наночастиц на здоровье человека при производстве и применении нерудных наноматериалов строительного назначения. Наиболее опасными, с точки зрения профессиональных экспозиций, являются такие процессы, как создание и нанесение наноразмерных покрытий, а также процессы размола, резки, очистки или освобождения оборудования от пыли [6]. Поэтому, для уменьшения риска здоровью работников, подвергающихся воздействию наночастиц, необходима разработка мероприятий и рекомендаций, направленных на профилактику их негативного воздействия. Данная система мер должна основываться на глубоких знаниях о путях и механизмах их токсического воздействия.

Таким образом, изучение закономерностей и механизмов токсического действия наночастиц горных пород различного генезиса является актуальным направлением в сфере современного строительного материаловедения. Развитие данного направления, по нашему мнению, сдерживается, прежде всего, отсутствием надежных методик и подходов, позволяющих определять данные параметры в образцах горных пород. Поэтому целью данной работы являлась оценка возможности применения методологического системного подхода, сочетающего в себе комплексные исследования как физико-химических, так и токсикологических характеристик образцов горных пород различного генезиса.

Предлагаемая схема методологического системного подхода представлена на рис. 1.

На основании анализа минерально-сырьевой базы Архангельской области объектом нашего исследования был выбран базальт [7-10]. Выбор этой горной породы обусловлен, в первую очередь, высокой коррозионной и химической стойкостью, низкой теплопроводностью, высокой прочностью при низких температурах и долговечностью, хорошими ог- 


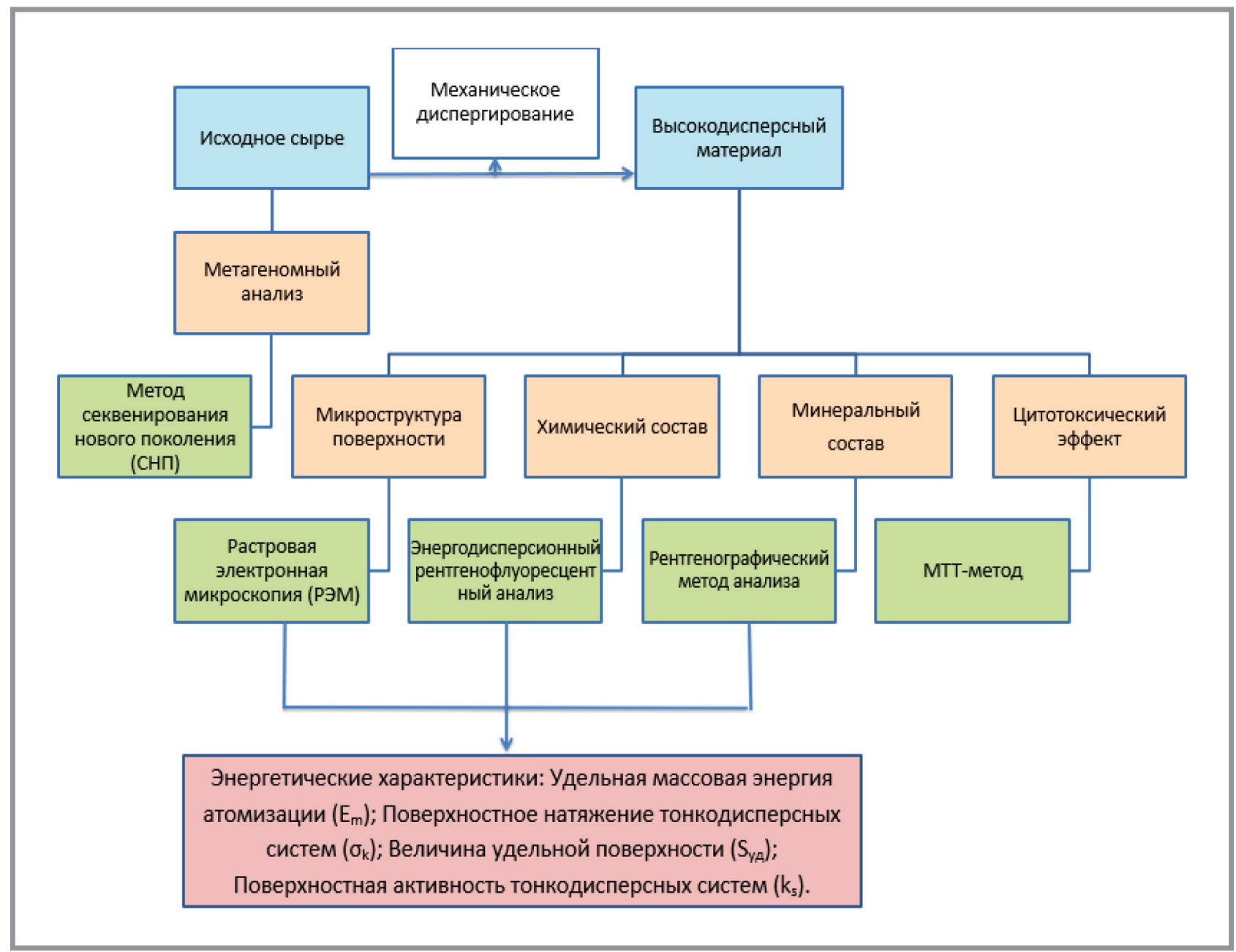

Рис. 1. Схема комплексного методологического подхода для токсикологической и физико-химической характеристики горных пород

неупорными свойствами, а также наличием его месторождения на территории Архангельской области. Эти характеристики делают данную породу широко применимой для дорожного и жилищного строительства в суровых природно-климатических условиях Севера и Арктики.

В числе основных физико-химических характеристик, определяющих потенциальную опасность для здоровья человека минеральных наночастиц, рассматриваются их природа (металлические, оксидные, углеродные, кремний-содержащие), состав (нанокомпозитные материалы), растворимость в воде и биологических жидкостях, заряд частицы, адсорбционная емкость, устойчивость к агрегации, гидрофобность, адгезия к поверхностям, способность к генерации свободных радикалов [11]. 
Вместе с тем, параметром, позволяющим оценить способность наночастиц (наносистем) к трансформационным превращениям, на наш взгляд, является их поверхностная активность $\left(\mathrm{k}_{\mathrm{S}}\right)$ [12-13]. Данный параметр показывает долю свободной поверхностной энергии, полученной в результате механической активации сырья, относительно общего энергетического запаса, заложенного в горной породе в процессе генезиса. Он рассчитывается исходя из химического состава материала (отражается в его удельной массовой энергии атомизации $\left(\mathrm{E}_{\mathrm{m}}\right)$ [9]), удельной поверхности системы $\left(\mathrm{S}_{\text {уд }}\right)$ и свободной поверхностной энергии единицы площади поверхности, численно равной поверхностному натяжению $\left(\sigma_{\mathrm{k}}\right)$ [14-15]. В [16-17] нами рассмотрены методические аспекты определения данных параметров. Таким образом, поверхностная активность учитывает способность высокоразвитой поверхности материала к самопроизвольным процессам компенсации избыточной поверхностной энергии и численно равна доли общего запаса потенциальной энергии системы, перешедшей в свободную поверхностную энергию при механоактивации сырья [18].

Однако для определения токсичности и влияния на состояние здоровья горных пород различного происхождения при производстве строительных материалов рассмотренные выше физико-химические параметры должны быть дополнены специфическими исследованиями по определению характера и видов биологически активных материалов, содержащихся непосредственно на поверхностях сырья, тонкодисперсных (микро- и нано-) частиц, а также определением цито- и генотоксичности последних.

Целесообразным представляется использование для решения этих задач таких новейших методов, как метод секвенирования нового поколения (СНП) и МТТ-метод определения жизнеспособности клеточных культур. СНП представляет собой сложный высокопроизводительный диагностический и прогностический молекулярно-генетический метод, который может быть использован для определения бактериологического (токсикологического) компонента различных природных образцов органического происхождения [19]. МТТ-метод представляет собой колориметрический тест для оценки метаболической активности клеток в специальных системах по изменению оптической плотности при 590 нм и 620 нм [20]. 


\section{Методическая часть}

Опытные образцы базальта были отобраны из месторождения «Мяндуха» (Архангельская область). Предварительно, перед началом экспериментов, сырьевые материалы горной породы были отмыты от глинистых включений и доведены до постоянной массы при температуpe $40 \pm 2^{\circ} \mathrm{C}$. Опытные тонкодисперсные образцы получали механическим измельчением сырья на планетарной шаровой мельнице Retsch PM100. Опытным путем были подобраны оптимальные условия измельчения, позволяющие получить максимальную степень дисперсности и хорошую воспроизводимость результатов. Для определения размерных характеристик полученных тонкодисперсных образцов базальта использовали метод фотонно-корреляционной спектроскопии, реализуемый на анализаторе размеров частиц и дзета-потенциала Delsa Nano.

Химический анализ полученных высокодисперсных фракций проведен методом рентгенофлуоресцентной спектроскопии на спектрометре Shimadzu EDX-800 HS.

Удельную массовую энергию атомизации $\left(\mathrm{E}_{\mathrm{m}}\right)$ анализируемого образца рассчитывали, исходя из стандартной теплоты образования химических соединений, определяющих минеральный состав сырья, учитывая при этом истинную плотность материала ( $\rho)$. Значения истинной

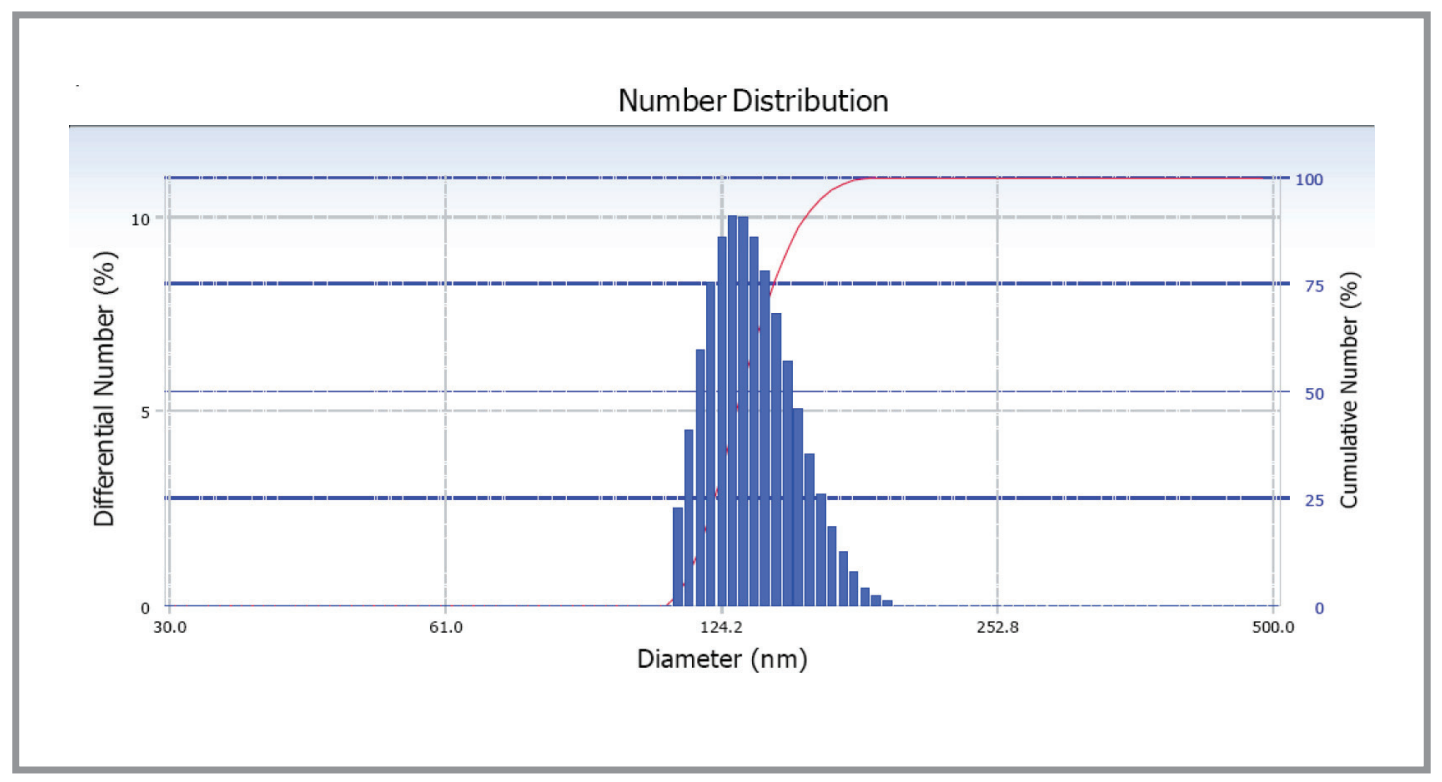

Puc. 2. Фракционное распределение полученного тонкодисперсного образца 
плотности испытуемого образца определялись экспериментально пикнометрическим методом.

Поверхностное натяжение тонкодисперсных систем базальта $\left(\sigma_{k}\right)$ рассчитывали по методу ОВРК, основанному на экспериментальном определении угла смачивания поверхности анализируемых образцов эталонными жидкостями. В качестве эталонных жидкостей использовали декан, этиленгликоль, глицерин и дистиллированную воду.

Величину удельной поверхности $\left(\mathrm{S}_{\text {уд }}\right)$ измеряли на приборе ПСХ10а методом газопроницаемости Козени-Кармана.

Поверхностную активность тонкодисперсных систем исследуемых горных пород рассчитывали, исходя из выражения (1):

$$
\mathrm{k}_{\mathrm{s}}=\frac{\sigma_{\mathrm{k}} \mathrm{S}_{\mathrm{yд}}}{\mathrm{E}_{\mathrm{m}}} \text {. }
$$

Оценку микробиологического загрязнения поверхности полученных опытных образцов базальтовых материалов проводили методом секвенирования нового поколения (СНП). С этой целью был проведен метагеномный анализ, который позволил определить видовое разнообразие микроорганизмов на поверхности исследуемых объектов без выделения и культивирования. Высокопроизводительная технология секвенирования была реализована на коммерческой платформе Illumina MiSeq и включала следующие этапы: подготовку библиотек микроорганизмов, упорядочение и анализ полученных данных. Для анализа генетических вариантов использовалось программное обеспечение, предоставленное Illumina (Real Time Analysis. V.1.18 и Miseq Reporter).

Цитотоксический эффект базальтовых наночастиц изучали методом МТT. МТТ-метод определения жизнеспособности клеточных культур заключается в способности живых клеток превращать растворимый желтый бромид 3-(4,5-диметилтиазол-2-ил)-2,5-тетразолия (MTT) в нерастворимые пурпурно-синие внутриклеточные кристаллы MTT-формазана (MTT-ф). Нежизнеспособные мертвые клетки такой способностью не обладают. Интенсивность превращения МTТ в МТТ-ф отражает общий уровень цитотоксичности наночастиц базальта. Статистический анализ был выполнен с использованием программного обеспечения GraphPad prism версии 5.0. Процентная жизнеспособность клеток рассчитывалась по формуле (2): 
ЗКизнеспособность клеток (\%) =

$=\left(\frac{\text { Средняя абсорбация обработанных клеток }}{\text { Средняя абсорбация контрольных клеток }}\right) \cdot 100$.

\section{Обсуждение результатов}

В результате механического диспергирования сырьевых материалов горных пород были получены фракции базальта со средней размерной характеристикой $-135 \pm 15$ нм (рис. 2).

В табл. 1 представлен химический состав (в пересчете на оксиды) основных компонентов анализируемой системы.

В табл. 2 приведены результаты расчета энергетических характеристик тонкодисперсной системы исследуемой горной породы.

Полученные данные показывают, что исследуемый материал обладает развитой активной поверхностью, что может являться благоприятным фактором для адсорбции различных форм бактерий и микроорганизмов.

Таблица 1

Химический состав минерального сырья

\begin{tabular}{|c|c|c|c|c|c|c|c|}
\hline \multicolumn{7}{|c|}{ Содержание оксидов, мас. \% } \\
\hline $\mathrm{SiO}_{2}$ & $\mathrm{MgO}$ & $\mathrm{Al}_{2} \mathrm{O}_{3}$ & $\mathrm{Na}_{2} \mathrm{O}$ & $\mathrm{Fe}_{2} \mathrm{O}_{3}$ & $\mathrm{CaO}$ & $\mathrm{K}_{2} \mathrm{O}$ & п.п.п. \\
\hline \multicolumn{7}{|c|}{ Базальт месторождения «Мяндуха» } \\
\hline 47,75 & 14,60 & 13,80 & 0,89 & 13,09 & 8,29 & 0,32 & 1,26 \\
\hline
\end{tabular}

Таблица 2

Энергетические характеристики образцов

\begin{tabular}{|c|c|c|c|c|}
\hline Образец & $\begin{array}{c}\mathbf{E}_{\mathrm{m}} \cdot \mathbf{1 0}^{-3}, \\
\mathbf{K Д} \% / \mathbf{K} \mathbf{\Gamma}\end{array}$ & $\mathbf{S}_{\mathrm{yg}}, \mathbf{M}^{2} / \mathbf{k} \mathbf{\Gamma}$ & $\begin{array}{c}\sigma_{\mathrm{k}} \cdot \mathbf{1 0}^{3}, \\
\text { Дж} / \mathbf{M}^{2}\end{array}$ & $\mathbf{k}_{\mathrm{s}} \cdot \mathbf{1 0}^{5}$ \\
\hline Базальт & 26,56 & 1243 & 12,00 & 5,6 \\
\hline
\end{tabular}


Для токсикологической характеристики базальта проведен метагеномный анализ сырьевого материала (анализ микробного разнообразия) в исследовательской лаборатории стволовых клеток и молекулярной биологии Мадрасского технологического института (Индия). Результаты исследований представлены на рис. 3.

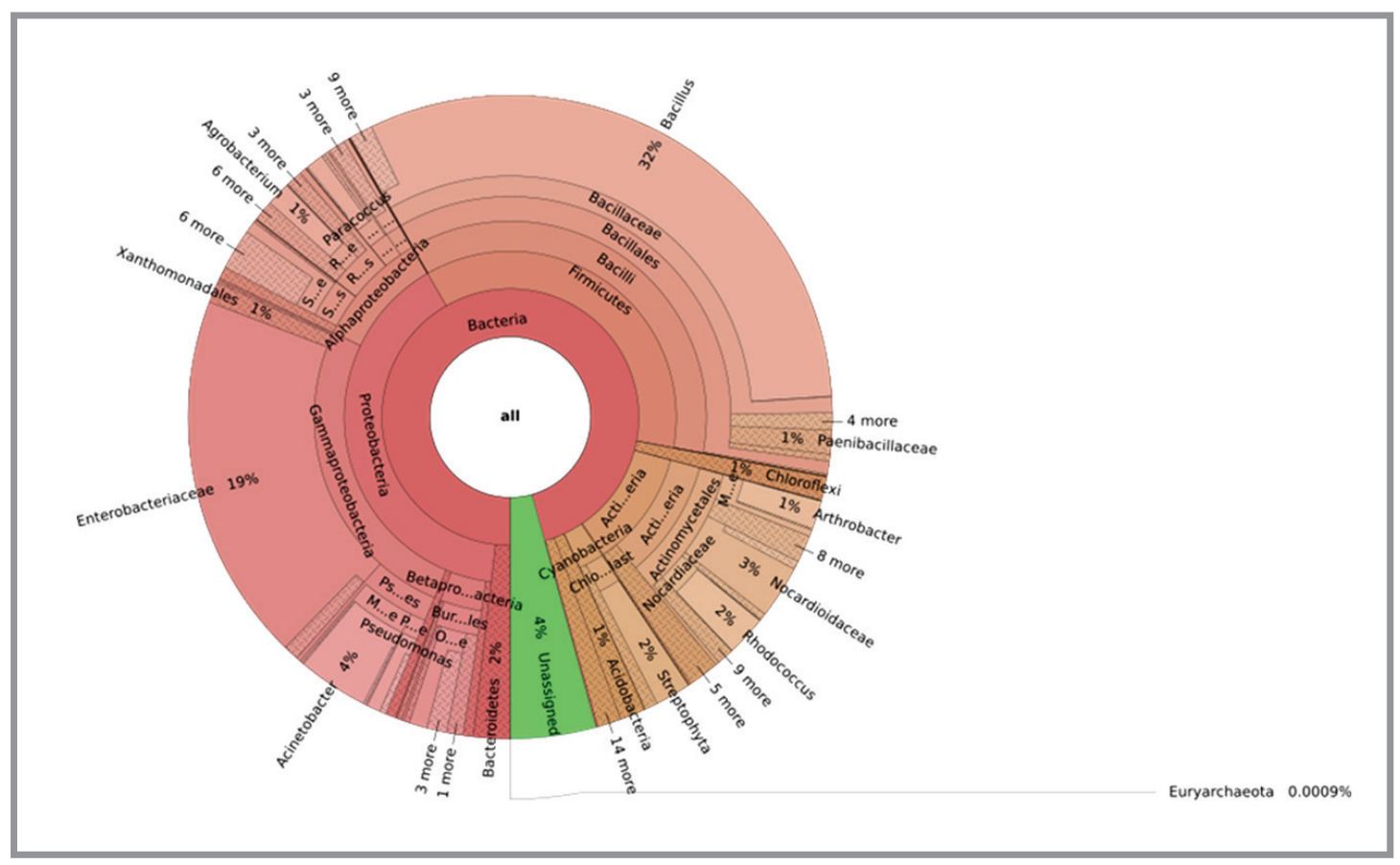

Рис. 3. Метагеномный анализ образца базальта

Данные секвенирования и метагеномный анализ показали, что поверхность образца базальта содержит различные группы микроорганизмов (род Bacillus и род Enterobacteriaceae).

Однако результаты исследования тонкодисперсных образцов методом МТТ показали, что базальтовые наночастицы не проявили никакой токсичности для клеток HEK-293 в течение 48 часов до концентрации реагента 100 ммоль/л. Значение концентрации, вызывающее $50 \%$-ное ингибирование роста популяции клеток IC50, нельзя было рассчитать из-за более чем $80 \%$-ной жизнеспособности клеток, что доказывает нетоксичную природу базальтовых наночастиц (рис. 4).

Таким образом, в качестве обобщающих результатов исследований можно отметить следующее: установлено, что базальт, обладая высокой поверхностной активностью, способен сорбировать наповерхности частиц 


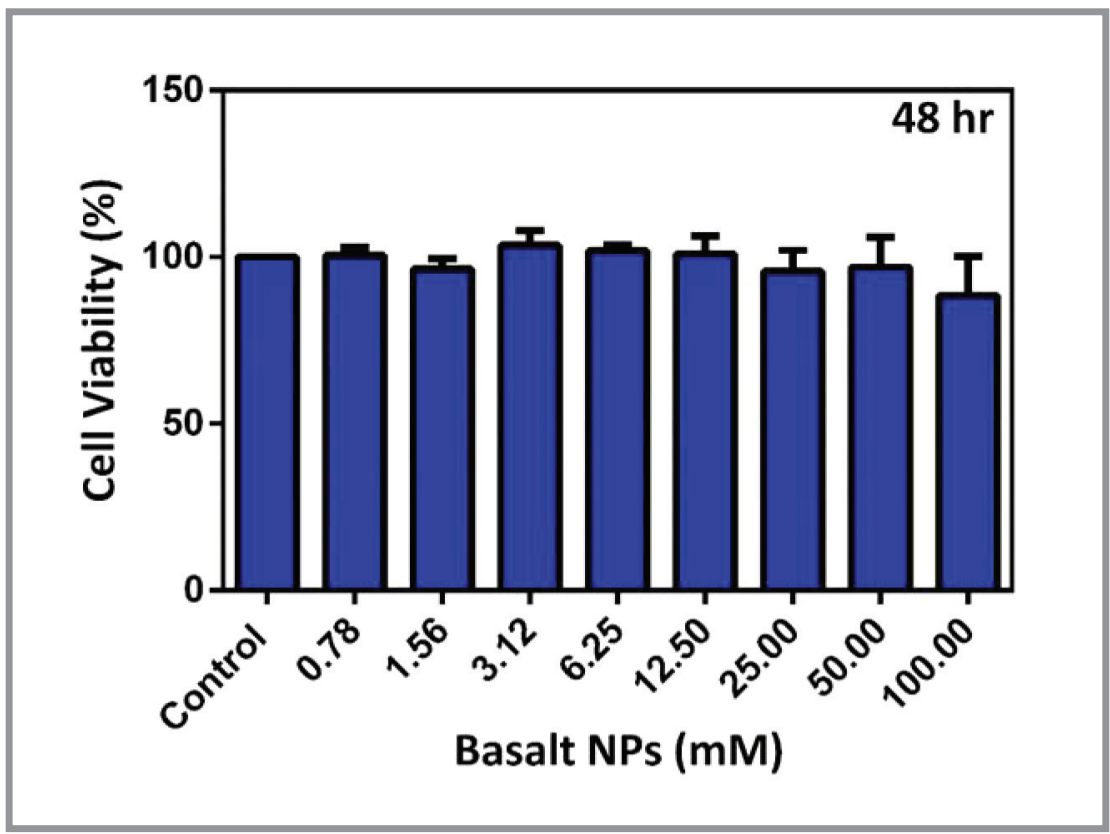

Puc. 4. Цитотоксичность базальтовых наночастиц на клетки НЕК-293 в зависимости от дозы в течение 48 часов. Данные представляют собой среднее \pm стандартное отклонение одиночного независимого эксперимента

значительное количество микроорганизмов различных видовых групп, что представляет собой потенциальную опасность микробиологического заражения - данный факт необходимо учитывать при переработке сырья в технологических процессах. Вместе с тем отмечена нетоксичная природа самих наночастиц базальта. Предложенная принципиальная схема комплексного подхода может быть рекомендована для оценки физикохимических и токсикологических свойств горных пород.

Исследование выполнено при финансовой поддержке РФФИ в ралках научного проекта № 16-53-45019 ИНД_а.

\section{Библиографический список:}

1. Годылчук А.Ю. Экология наноматериалов. - М: Бином, 2012. - 272 с.

2. Третьяков Ю.Д., Гудилин E.A. Основные направления фундаментальных и ориентированных фундаментальных исследований в области наноматериалов // Альтернативная энергетика и экология. - 2009. - № 6. - С. 39-67. 
3. Лесовик В.С., Строкова В.В. О развитии научного направления «Наносистемы в строительном материаловедении» // Строительные материалы. - 2006. № 9. / Наука № 8. - С. 18-20.

4. Карпов А.И. Развитие нанотехнологий в строительстве - актуальнейшая задача ученых и инженеров // Нанотехнологии в строительстве. - 2013. - Том 5, № 2. - C. 43-54. - URL: http://nanobuild.ru/ magazine/nb/Nanobuild_2_2013. pdf (дата обращения: 01.11.2017).

5. Арталонова О.В., Сергуткина О.Р., Коротких Д.Н., Чернышов Е.М. Зольгель синтез наноразмерных частиц $\mathrm{SiO} 2$ для модифицирования структуры цементного камня // Нанотехнологии в строительстве. - 2010. - Том 2, № 1. C. 9-17. - URL:http://nanobuild.ru/magazine/nb/Nanobuild_1_2010.pdf (дата обращения: 01.02.2016).

6. Фахутдинова Л.М., Халиуллин Т.О., Зальялов Р.Р. Токсичность искусственных наночастиц // Казанский медицинский журнал. - 2009. - С. 578-584.

7. Danilov V.E., Ayzenshtadt A.M., Bessert O.B. Optimization of the composite binder on the basis of basalt and polymineral sand / V. E. Danilov, A.M. Ayzenshtadt, O.B. Bessert // The Conference proceedings «International Conference on Electrical, Electronics, and Optimization Techniques» (ICEEOT-2016). - 2016. P. 192-195.

8. Drozdyuk T., Aizenshtadt A., Tutygin A., Frolova $M$. Basalt fiber insulating material with a mineral binding agent for industrial use / T. Drozdyuk, A. Aizenshtadt, A. Tutygin and M. Frolova // IOP Conference Series: Materials Science and Engineering. - 2016. - Vol. 124. N 1. - p. 1-4.

9. Стенин А.А., Айзенштадт А.М., Шинкарук А.А., Делидов М. Л., Фролова М. А. Минеральный модификатор поверхности строительных материалов из древесины / Строительные материалы. - 2014. - № 10. - С. 51-54.

10. Фоличев С.В., Бабиевская И.З., Дергачева Н.П., Носкова О.А., Кренев В.А. Оценка и модифицирование исходного состава габбро-базальтовых пород для получения минеральных волокон и изделий каменного литья // Неорганические материалы. - 2010. - Т. 46, № 10. - С. 1240-1245.

11. Анциферова И.В., Макарова Е.Н. Методы производства наноматериалов и возможные экологические риски / И.В. Анциферова, Е.Н. Макарова // Вестник ПНИПУ. Машиностроение, материаловедение. - 2013. - Т. 15, № 4. - С. 59-67.

12. Вешнякова Л.А., Айзенштадт А.М., Фролова М.А. Оценка поверхностной активности высокодисперсного сырья для композиционных строительных материалов / Ф Физика и химия обработки материалов. - 2015. - № 2. - С. 68-72.

13. Абраловская И. Р., Айзенштадт А. М., Фролова М. А., Вешнякова Л. А., Тутьгин А. С. Энергетика высокодисперсных композитов горных пород / / Нанотехнологии в строительстве. - 2013. - № 3. - С. 56-65. 
14. Абраловская И.Р., Айзенштадт А.М., Лесовик В.С., Вешнякова Л.А., Фролова M.A., Казлитин C.A. Расчет энергоемкости горных пород - как сырья для производства строительных материалов // Промышленное и гражданское строительство. - 2012. - № 10. - С. 23-25.

15. Слирнов В.А., Королев Е.В., Альбакасов А.И. Размерные эффекты и топологические особенности наномодифицированных композитов // Нанотехнологии в строительстве. - 2011. - Toм 3, № 4. - C. 17-27. - URL: http://nanobuild.ru/ magazine/nb/Nanobuild_4_2011.pdf (дата обращения: 01.11.2017).

16. Gayda J., Ayzenshtadt A., Tutygin A., Frolova M. Organic-Mineral Aggregate for Sandy Subsoil Strengthening / J. Gayda, A. Ayzenshtadt, A. Tutygin, M. Frolova // Procedia Engineering. - 2016. - Vol. 143. - P. 90-97.

17. Фролова М.А., Тутыгин А.С., Айзенштадт А.М., Лесовик В.С., Махова Т.А., Поспелова T.A. Критерий оценки энергетических свойств поверхности // Наносистемы: физика, химия, математика. - 2011. - Т. 2, № 4. - С. 120-125.

18. Вешнякова Л.А., Дроздюк Т.А., Айзенштадт А.М., Фролова М.А., Тутыгин А.С. Поверхностная активность кремнесодержащих горных пород // Материаловедение. - 2016. - № 5. - С. 45-48.

19. Ansorge W.J. Next-generation DNA sequencing techniques / W.J. Ansorge // N Biotechnol. - 2009. - Apr; 25(4). - P. 195-203.

20. Wilson Anne P. Chapter 7: Cytotoxicity and viability / Anne P. Wilson // Animal Cell Culture: A Practical Approach Oxford: Oxford University Press. - 2000. Vol. 1. - 334 p. - ISBN 978-0-19-963796-6.

\section{УВАЖАЕМЫЕ КОЛЛЕГИ!}

ПРИ ИСПОЛЬЗОВАНИИ МАТЕРИАЛА ДАННОЙ СТАТЬИ

ПРОСИМ ДЕЛАТЬ БИБЛИОГРАФИЧЕСКУЮ ССЫЛКУ НА НЕЁ:

Айзенштадт А.М., Фролова М.А., Шинкарук А.А. Комплексный методологический подход для определения токсикологических характеристик тонкодисперсных образцов горных пород // Нанотехнологии в строительстве. - 2017. - Том 9, № 6. - С. 91106. - DOI: dx.doi.org/10.15828/2075-8545-2017-9-6-91-106.

\section{Dear Colleagues!}

THE REFERENCE TO THIS PAPER HAS THE FOLLOWING CITATION FORMAT:

Ayzenshtadt A.M., Frolova M.A., Shinkaruk A.A. Comprehensive methodological approach to determine the toxicological characteristics of the highly dispersed rock samples. Nanotehnologii v stroitel'stve $=$ Nanotechnologies in Construction. 2017, Vol. 9, no. 6, pp. 91106. DOI: dx.doi.org/10.15828/2075-8545-2017-9-6-91-106. (In Russian). 